\title{
Compliance between ANSI/ACCA/ ASHRAE 180 and ANSI/ISA-95 for Maintenance Management
}

Key Words: Facility; operations management; ANSI/ISA-95; ANSI/ACCA/ASHRAE 180; standard operations procedures; product segment; process segment.

\begin{abstract}
Facility Management is an important part in the commercial buildings and installations lifecycle, which includes permanent checks and monitoring of all systems and installations, helping to achieve the organizational objectives. The execution of activities of Maintenance and Inspection is often redistributed to contracted service providers which raises the issue of managing and supervising the results of work done. The major factor for proper execution of distributed tasks is the formalization of the activities in manner of who-what-when-why-how has to be done to accomplish the work. These rules have to be used as guidelines during the tasks execution and for the purpose of managing and supervising the overall progress of maintenance activities.
\end{abstract}

\section{Introduction}

Each facility operations management organization has to develop its own organizational standard procedures for maintenance and inspection activities, depending on the types of the equipment, installations and systems used in their case. Usually these procedures are taken from the technical documentation supporting the asset's proper usage. Different approach to create Standard Operations Procedures is to use the practices described in the standard ANSI/ ASHRAE/ACCA Standard 180-2008 Standard Practice for Inspection and Maintenance of Commercial Building HVAC Systems. Once the organization has developed the Standard Operations Procedures they have to be summarized into an Asset Management System in order to achieve best benefits of the Asset Management effort.

An Asset Management System provides a structured approach for the development, coordination and control of activities undertaken on assets by the organization over different life cycle stages, and for aligning these activities with its organizational objectives.

a) Creating an asset management system provides benefits in itself.

The process of implementing an asset management system can require significant time effort and expense; however, the organization does not need to wait until the entire system is fully operational to begin accruing benefits. The benefits, or quick wins, in areas such as risk reduction, opportunity identification or process improvement can be identified early in the implementation, and can be exploited to demonstrate returns and gain stronger stakeholder support.

b) Top management benefits from new insights and cross functional integration.

An asset management system can help in gaining an understanding of assets, their performance, the risks associated with managing assets, investment needs, and asset value as an input to decision making and organizational strategic planning.

c) Financial functions benefit from improved data and linkages.

Integration of an organization's strategic asset management plan (SAMP), with its long-term financial plans can enable the balancing of short-term financial needs with the needs of medium-term activity plans, and with the much longer-term plans that some assets require.

d) Many parts of the organization benefit from an asset management system.

An asset management system touches many parts of the organization as HR, Control Systems, communicating with employees, suppliers and contracted service providers, etc. [1]

\section{ANSI/ACCA/ASHRAE 180 Standard Practices}

Standard 180 describes the minimum acceptable level of maintenance for commercial building HVAC systems. Other Standards or guidance documents may establish more specific or rigorous requirements that apply to certain buildings.

Where applicable, those requirements should be followed or considered [2]. Therefore this standard may be used by Facility Operations Organizations as guidelines in scheduling and execution of activities as inspection and maintenance when there aren't such.

ANSI/ACCA/ASHRAE 180 defines a procedure to determine the required inspection and maintenance tasks for each subsystem or piece of equipment in a building. The procedure is as follows:

1. Referring to the HVAC equipment and systems inventory prepared, prepare a listing of the different equipment or subsystem types that exist in the building.

2. Using the list, identify from the 25 tables (tables 5-1 through 5-25 from the standard) those that apply to the HVAC systems and equipment in the building.

If the HVAC system for your facility contains subsystems or equipment that is not found in the tables in this section, use inspection and maintenance items from tables 
for similar subsystems or equipment or create a new list of appropriate items.

3. At a minimum, the maintenance plan for the building shall include each of the inspection and maintenance tasks from all of the applicable tables.

4. The maintenance program may include other inspection and maintenance tasks to preserve the ability of the subsystem or equipment to achieve acceptable thermal comfort, energy efficiency, and indoor air quality.

5. The standard shall not supersede equipment manufacturer's instructions and guidelines that may require more frequent or increased tasks [2].

The standard also consists 25 tables that cover all the activities and best practices during the execution of maintenance and inspection of the following HVAC and supporting installations: Air Distribution Systems; Air Handlers; Boilers; Chillers - Absorption; Chillers - Air Cooled; Chillers - Water Cooled; Coils and Radiators; Condensing Units; Control Systems; Cooling Towers and Evaporative Cooled Devices; Dehumidification and Humidification Devices; Economizers - Air Side; Engines, Microturbines; Fans (e.g., Exhaust, Supply, Transfer, Return); Fan Coils, Hot Water, and Steam Unit Heaters; Furnaces, Combustion Unit Heaters; HVAC Water Distribution Systems; Indoor Section Duct-Free Splits; Outside Air Heat Exchanging Systems; PTAC/PTHP (Package Terminal Air Conditioners or Heat Pumps); Pumps; Rooftop Units; Steam Distribution Systems; TerminalandControlBoxes (e.g., VAV, Fan Powered, Bypass); Water Source Heat Pumps.

Each table contains ordered tasks and the recommended frequency of each task execution. If unacceptable condition indicators or unacceptable performance is found during two successive inspections, the owner, or owner's designated representative, shall investigate and analyze possible causes. At a minimum, the following possible causes shall be investigated.

- Poor field practices - review inspection documentation and/or technician execution to ensure maintenance tasks are performed correctly.

- Insufficient time budgeted for tasks - review time budgeted to the technician to assure that reasonable time has been given to perform the tasks.

- Component repairs noted/pending/not made - inspect documentation to determine that repair or component replacement has been undertaken.

- Design issues - determine whether underlying design issues are causing successive failures.

- Obsolete equipment or components - determine whether the equipment or component has been in service beyond its useful life.

- Conditions outside of the HVAC system causing failure - investigate whether water leaks, vandalism, a problem in the building envelope or some other external factor is causing the problem.

Based on the analysis, the inspection frequency or the maintenance task shall be modified to resolve the deficiency [2].

\section{ANSI/ISA-95 Maintenance Operations Model}

The standard ANSI/ISA-95 (IEC 62264) defines the main objects and models used for data integration between the different levels of information systems (i.e. BMS - Building Management System, ERP, SCM, etc.) in the areas of Production, Maintenance, Quality and Inventory (figure 1).

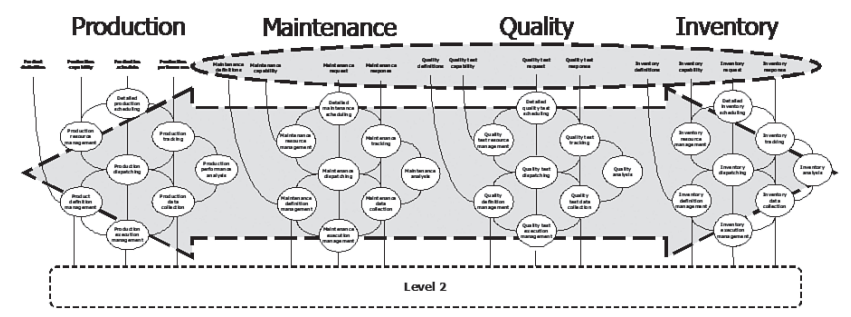

Figure 1. Operations Model on level 3 [4]

Regardless the fact that this standard is industrial, there are some considerations, leading to the conclusion that it is applicable in the field of Building Facility Management:

- The information systems in the hierarchical structure of Facilities are the same (Building Management Systems refer to SCADA, DCSs and PLCs).

- The maintenance operations i.e. Resource Management, Definition Management, Detailed Maintenance Scheduling, Dispatching and Execution, etc. are the same as described in the standard (figure 2).

- Using standard approach allows freedom in objects description.

- Computerized Maintenance Management System (CMMS) built based on the standard ANSI/ISA95 give configurability, scalability, short deployment terms, low price and easy integration.

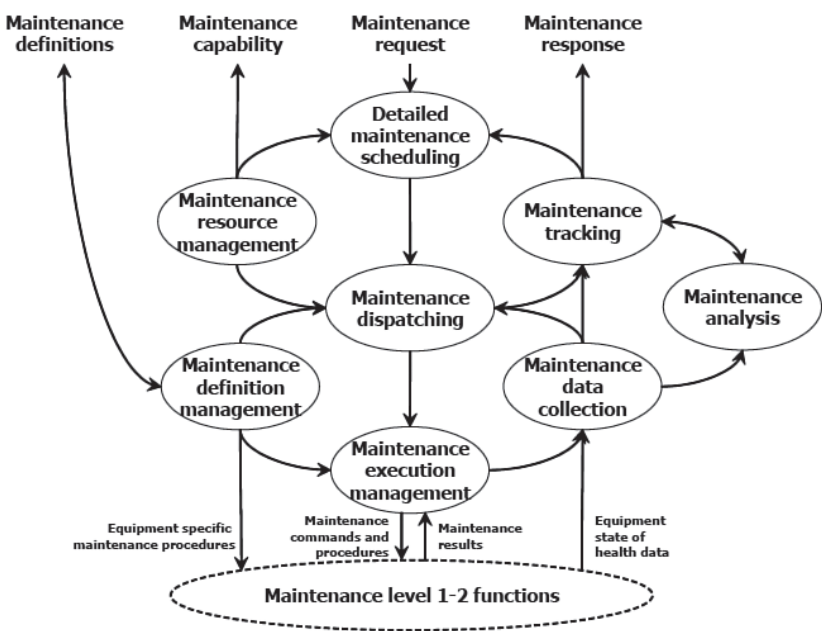

Figure 2. Maintenance Operations Model [4]

Maintenance operations tracks and directs the activities that maintain the equipment and tools to ensure their 
availability for exploitation and insure scheduling for periodic or preventive maintenance. Also provides the response (alarms) to immediate problems. The model defines what maintenance activities should be done and the relative sequencing of those activities, not how they should be performed in a specific organization structure. Different companies may have a different organization of roles and assignment of roles to personnel or systems.

The model illustrates the major information flows between activities, other information flows are defined in each activity's definition.

General maintenance activities typically include:

- Providing maintenance for existing facilities.

- Providing preventative, predictive, and reliability centered maintenance.

- Providing equipment monitoring activities to anticipate failure, including equipment self-check and diagnostic activities.

- Developing maintenance cost and performance reports.

- Coordinating and monitor outside contract work effort.

- Supervision of requested maintenance.

- $\quad$ Reporting on performed maintenance, including used spare parts, report maintenance labor and report on maintenance costs.

- Coordinating planned work with operators and plant supervision.

- Monitoring and update maintenance history file.

The activity objects and relations for Maintenance operations are given in the Maintenance Information Model (figure 3).

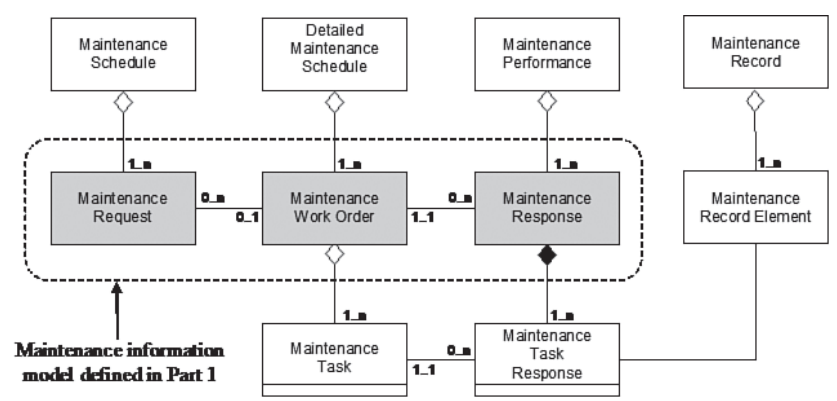

Figure 3. Maintenance Information Model [3]

They are as follows:

- A maintenance schedule is a collection of planned maintenance requests.

- A detailed maintenance schedule is a collection of maintenance work orders.

- A maintenance work order is made up of a set of maintenance tasks, required to complete the work.

- A maintenance performance is a collection of maintenance responses.

- A maintenance response is made up of a set of maintenance task responses, documenting the work done and resources used for maintenance tasks.

- A maintenance task may have zero or more main- tenances task responses associated with it [4].

Furthermore these objects are used in the models of Maintenance Scheduling and Maintenance Execution as shown in figures 4 and 5.

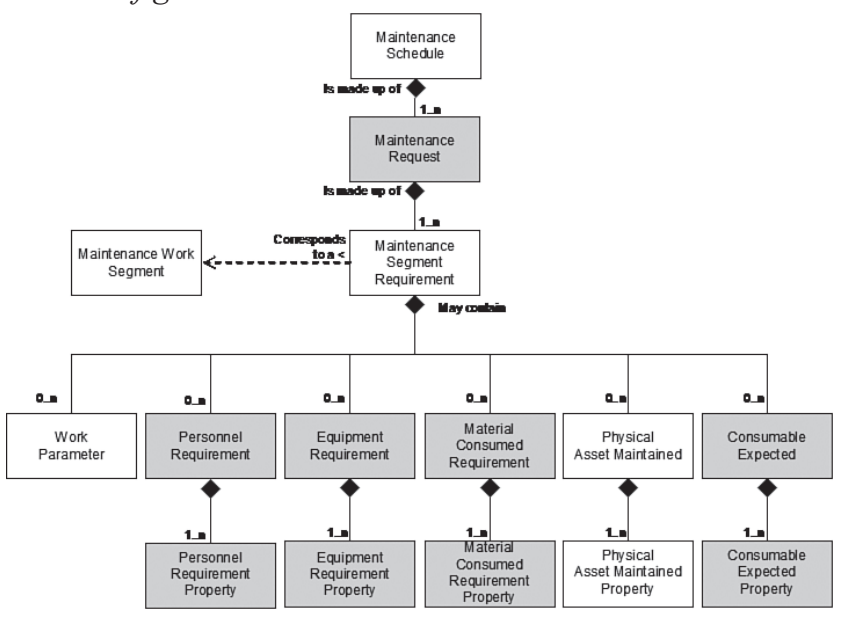

Figure 4. Maintenance Schedule Model

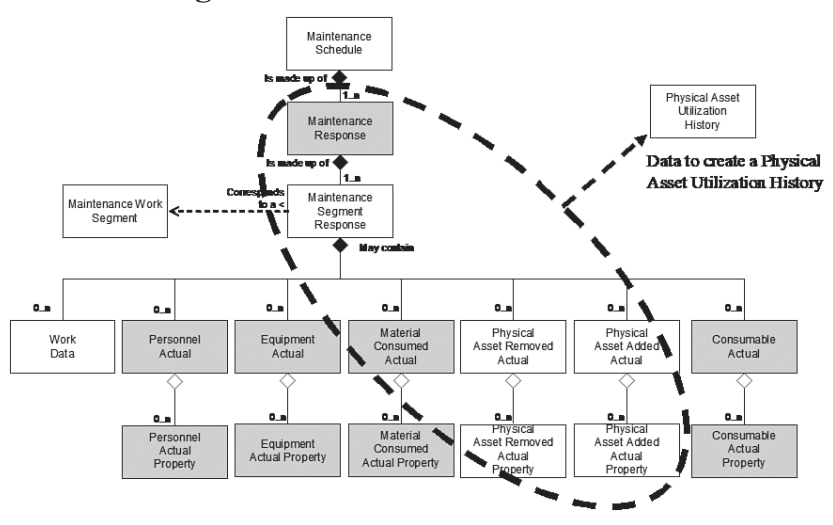

Figure 5. Maintenance Performance Model

The connection between the two standards can be made using the model of Operation Definitions. This model describes the objects and relations between an Operation Definition and the main resources specified for it. An Operation Definition is associated to (1 . n) Operation Segments which are a collection of specified Personnel (with specified set of skills), Equipment, Tools, and Material (spare parts, consumables, etc.) (figure 6). This model and the previous two are related in manner of: What resources are "specified", what resources are "required" and with what resources the work is actually performed.

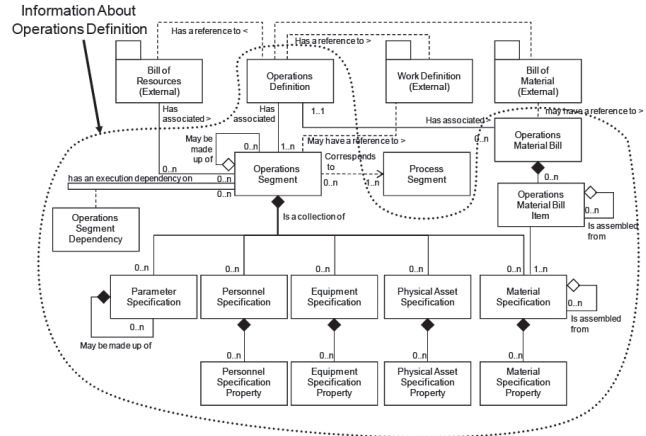

Figure 6. Operations Definition Model [5] 


\section{Classifying Standard Operations Procedures into Operations Definitions for Scheduling}

For the purpose of Scheduling and Execution of the Maintenance Tasks, the Standard Practices have to be classified to Operations Definitions.

The Standard Practices in ANSI/ACCA/ASHRAE 180 are divided by installations, the activities have Frequency and may be separated once more by Type - Maintenance or Inspection as it is given in the title of the standard.

Each installation corresponds to Equipment Class or an Asset Class which is implemented by such, from ANSI/ ISA-95 the definition of which is a grouping of equipment with similar characteristics for purposes of scheduling and planning.

Using Equipment Classes, the Task Type and the Task Frequency for each installation there can be maximum twelve Operations Definitions but according the ANSI/ACCA/ASHRAE 189 standard tables they rarely exceed five.

For Example one Maintenance Operation Definition for Air Handlers Semi-Annually Inspection and Maintenance (Maintenance Operations follow Inspection Operations) consists the following steps:

- Check control system and devices for evidence of improper operation. Clean, lubricate, repair, adjust or replace as needed to ensure proper operation.

- Check P-trap. Prime as needed to ensure proper operation.

- Check fan belt tension. Check for belt wear and if necessary to ensure proper operation. Check sheaves for evidence of improper alignment or evidence of wear and correct as needed.

- Check variable frequency drive for proper operation. Correct as needed.

- Check for proper operation of cooling or heating coil for damage or evidence of leaks. Clean, restore or replace as required.

Each of these operations is associated to Operations Segment which may be located in a separate place but requires specified Equipment (or tools), Personnel or Materials (Spare Parts or Consumables).

In Maintenance Schedule Model Maintenance Request corresponds to Maintenance Definition and Maintenance Work Segment to an Operations Segment.

The Schedule may be made up of Maintenance Requests such as Air Handlers Semi-Annually Inspection including Maintenance Work Segments as described above. The Maintenance Work Segment is the connection between the Maintenance Scheduling and Maintenance Performance Models.

\section{Conclusions}

Compliance of standards in different fields of application but comprising knowledge in same hierarchical level of information systems is essential part in Project Management when there are no studies available. On other hand most of the Building Management Systems do not cover Operations Management activities such as Planning and Scheduling, Resource Management, Dispatching and Work Management, Data Collection and Analysis.

Such activity coverage is inherent for MES/MOM systems built based on the standard ANSI/ISA-95. Using MES/MOM systems for Maintenance Operations Management, including for Facility Management is a step forward in the dawn of the 4th Industrial Revolution where Internet of Things (IoT), Augmented Reality, Smart Products (CPS) and Smart Machines (CPPS) will provide immediate information to the responsible personnel for the assets' current condition [6]. Using the MES/MOM structured data along with these new technologies will improve the quality of provided maintenance services by using relevant information, at the right time, at the right place, in the right form, to the right people.

\section{References}

1. ISO 55000:2014 Asset Management - Overview, Principles and Terminology. ISO, 2014.

2. ANSI/ASHRAE/ACCA Standard 180-2008 Standard Practice for Inspection and Maintenance of Commercial Building HVAC Systems. ANSI, 2012.

3. ANSI/ISA 95.00.03-2013. Enterprise-Control System Integration Part 3: Activity Models of Manufacturing Operations. ISA, 2013.

4. ANSI/ISA 95.00.04-2012 Enterprise-Control System Integration - Part 4: Objects and Attributes for Manufacturing Operations Management Integration. ISA, 2012.

5. B2MML-BatchML V0600. Manufacturing Enterprise Solutions Association (MESA International), 2013.

6. Filipov, V., P. Vasilev. Manufacturing Operations Management

- The Smart Backbone of Industry 4.0. - International Scientific Journal Industry 4.0, 1, Borovets, Bulgaria, December 2016. 


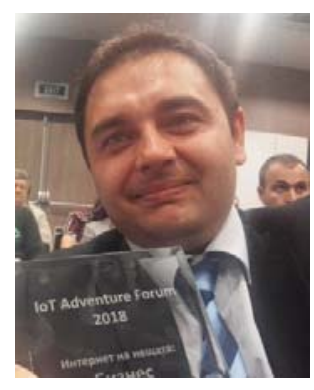

Dr. Plamen Vasilev is an assistant professor in Department of Industrial Automation in UCTM. His area of expertise is design of ANSI/ISA 95 based MES/MOM systems for purpose of Production and Maintenance Management. He is functional manager in NearSoft Ltd. with main responsibilities in project management, including gathering of customer requirements, analysis and design of solutions for manufacturing production and maintenance and customer support. He has six years of experience in design, implementation and integration of MES/MOM systems.

Contacts:

Department of Industrial Automation University of Chemical Technology and Metallurgy

8 Kl. Ochridski, 1756 Sofia, Bulgaria e-mail:plamen.vasilev@uctm.edu

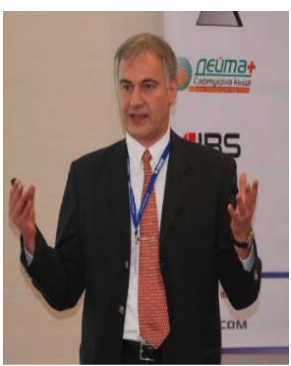

Vladimir Filipov, Chief Executive Officer, founded NearSoft Ltd. in 2006. He holds a Master of Science degree in Industrial Automation and has over 19 years in the software industry. He has been promoting and implementing Manufacturing Execution Systems world-wide during the last 18 years and helped $A B B$ to secure the position as world leader in the field of Collaborative Production Management. Mr. Filipov held the position of Product

Manager at $A B B$, prior to founding NearSoft.

\section{Contacts:}

NearSoft Ltd

Triaditsa 5A, 1000, Sofia, Bulgaria e-mail: vladimir.filipov@nearsoft.eu 


\section{Call for papers}

You are invited to submit a research paper for publication in ITC Journal

Journal Information Technologies and Control

Print ISSN 1312-2622

On-line ISSN 2367-5357

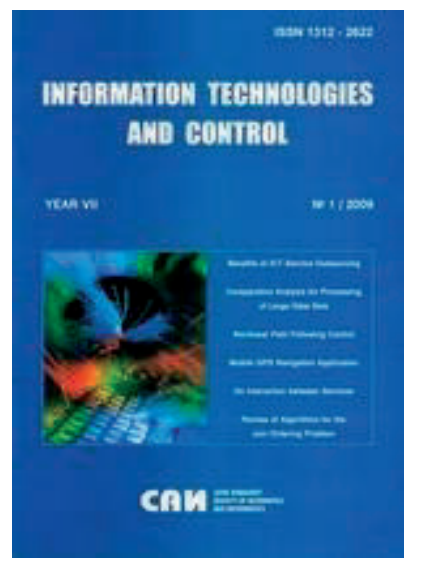

The Information Technologies and Control is an Online Open Access Peer-Reviewed International Journal started in 2002. It publishes original contributions including theoretical as well as application papers in the areas of information processing and control engineering. Topics include, but are not limited to: adaptive control, artificial intelligence, biological and medical systems, computer communication technologies, control of manufacturing systems, control of process systems, discrete event systems, high performance computing, identification and filtering, intelligent systems, multi-agent systems, network control systems,

operations research, optimal control, pattern recognition, robot control, robust control, signal and image processing, scientific computations, software technologies, information technologies and control in education. Survey articles will also be considered.

The journal publishes 4 regular issues per annum and/or some additional special thematic issues with selection of extended papers from international scientific events.

The journal "Information Technologies and Control" is abstracted/indexed in 17 data bases: Baidu Scholar, Celdes, CNKI Scholar (China National Knowledge Infrastructure), CNPIEC, EBSCO Discovery Service, Genamics JournalSeek, Google Scholar, J-Gate, JournalTOCs, Naviga (Softweco), Primo Central (ExLibris), ReadCube, ResearchGate, Summon (Serials Solutions/ProQuest), TDOne (TDNet), TEMA Technik und Management, WorldCat (OCLC).

Each paper obtains DOI.

For more Information and Author Guidelines visit www.degruyter.com/view/j/itc.

For author's convenience, we recommend the following steps.

\begin{tabular}{|l|}
\hline 1. Submit article to: sai.bg.office@gmail.com . \\
\hline $\begin{array}{l}\text { 2. Peer review process is now accelerated to save authors` valuable time. Authors will get } \\
\text { their Acceptance/Rejection Notification within } 20 \text { days of submitting paper. }\end{array}$ \\
\hline 3. All the accepted papers will be open accessible with full PDF download. \\
\hline 4. Corresponding author of the paper will get the soft copy of the journal. \\
\hline 5. Each accepted paper will be charged by publication fee of 70 Euro. \\
\hline
\end{tabular}

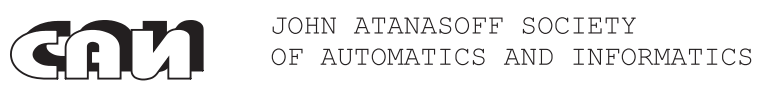

